\title{
LÍNEA JURISPRUDENCIAL EN MATERIA DE TOMA DE MUESTRAS BIOLÓGICAS DE ADOLESCENTES CONDENADOS, PARA INCLUSIÓN DE SU HUELLA GENÉTICA. ¿¿EL RECURSO DE NULIDAD FLEXIBILIZA SU RIGUROSIDAD?
}

\author{
ÁNgel ÁVILA CALDERóN* \\ Diego Palomo Vélez**
}

\section{1) INTRODUCCIÓN}

Debemos recordar que con la Ley $\mathrm{N}^{\circ} 19.696$, además de establecer un nuevo procedimiento penal, se regula un nuevo sistema recursivo, instaurando uno "coherente" y "compatible" con el nuevo modelo de enjuiciamiento basado en los "principios" 1 de oralidad, inmediación y celeridad (velando por respetar escrupulosamente la técnica recursiva asociada $^{2}$ ), brindando el adecuado protagonismo al juicio oral.

La reforma nos ofrece un modelo recursivo restringido, con un recurso extraordinario como verdadero protagonista, restringiendo la competencia del tribunal de alzada a cuestiones jurídicas, y solo mediante un caso muy excepcional (más bien doblemente excepcional, dada la interpretación que de ella han hecho nuestros tribunales), se ha permitido influir en la base fáctica establecidas por el tribunal de la instancia ${ }^{3}$. Sobre la crítica a esta regulación del derecho al recurso ya hemos dicho bastante en otras oportunidades ${ }^{4}$.

\footnotetext{
* Abogado, Fiscal Adjunto Jefe, Fiscalía local de Talca (CHILE). Correo electrónico: aavila@ minpublico.cl

** Abogado, Doctor en Derecho. Profesor de Derecho Procesal de la Universidad de Talca (ChILE). Correo electrónico: dpalomo@utalca.cl

1 Sobre la errada naturaleza y jerarquía que se ha asignado a la regla de la oralidad ya hemos dicho bastante en: PAlomo VÉLEZ, D. (2010). "Apelación, doble instancia y proceso civil oral. A propósito de la reforma en trámite”. Revista Estudios Constitucionales. Ańo 8, $\mathrm{N}^{\circ} 2$, pp. 465-524.

2 Palomo (2010) 469.

3 Horvitz Lennon, M. y López Masle, J. (2007) Derecho Procesal Chileno, La Etapa Intermedia o de Preparación del juicio, la Prueba, La Etapa del Juicio Oral, los Recursos, los Procedimientos Especiales, Ejecución de las Sentencias condenatorias y de las Medidas de Seguridad, la Acción Civil en el Proceso Penal”. Santiago: Editorial Jurídica de Chile. T.II, pp. 349 y 350. "Va a surgir de este modelo, un régimen de recursos que restringe las posibilidades de impugnación de las resoluciones de primera instancia y limita el ámbito de control superior en los términos necesarios para asegurar el "principio de inmediación".

4 Palomo Vélez, D. y Valenzuela Villalobos, W. (2011) "Declaraciones de inadmisibilidad del recurso de nulidad laboral como restricción indebida al derecho al recurso: Jurisprudencia correctiva de la E. Corte Suprema". Revista de Derecho Universidad Católica del Norte. Año 18, N², pp. 399-415; Palomo (2010).
} 
Ahora bien, desde la dogmática penal se ha señalado fundamentalmente que el recurso de nulidad no puede ser asimilado al recurso de casación y, por el contrario debe ser entendido como un mecanismo impugnatorio ajeno al excesivo rigor formalista propio del recurso de casación 5 .

Lamentablemente, en sede nulidad y con alarmante frecuencia, se suceden con mayor profusión las resoluciones de las Cortes de nuestro país que, echando mano a la rigurosidad del examen de admisibilidad como garantía de su excepcionalidad, y recurriendo al carácter extraordinario y de derecho estricto del recurso que regula nuestro $\mathrm{CPP}$, sin más, declaran su inadmisibilidad. De esta forma, sin mutar el argumento ni su soporte normativo, son decenas los recursos de nulidad que fracasan en su intento por trasponer el férreo tamiz de admisibilidad de nuestras Cortes, el que a nivel de Corte Suprema se torna en un desafío francamente mayor. Así, motivos formales como: la ausencia de peticiones concretas ${ }^{6}$; la solicitud de anular solo el juicio oral sin requerirse a su vez la invalidación de la sentencia ${ }^{7}$; la solicitud conjunta de nulidad del juicio y la sentencia, sin plantearse petición alguna posible de juzgar para el caso de accederse ${ }^{8}$; no individualizarse las garantías constitucionales que se estiman infringidas - para el caso de la causal de nulidad del art. 373 letra a) CPP - sin ser suficiente con señalar un artículo de la CPR, ni tampoco señalar cómo estas se vulnerarían'; o que el vicio reclamado se refiere más allá de la garantía que se habría vulnerado "a una supuesta infracción a la valoración de la prueba conforme a derecho en la sentencia, y a la disconformidad en cuanto a la forma como lo hizo el Tribunal de Juicio Oral en lo Penal"10, entre otros motivos diversos, se suceden con cada vez mayor periodicidad y no menor preocupación, dando paso a una suerte de blindaje del juicio que no pocas veces ha servido a nuestros jueces para esquivar o evitar una motivación más consistente y exhaustiva. Lo anterior pone en seria duda el cumplimiento de la garantía constitucional del acceso al recurso, como si no fuera bastante con las limitaciones propias del recurso de nulidad ${ }^{11}$.

Como lo hemos señalado anteriormente "uno de los puntos que más se destacó por los partidarios de este nuevo sistema recursivo fue que se configuraba un recurso de nulidad como un mecanismo de impugnación

Palomo y Valenzuela (2011) 408.

Corte Suprema. 4 de octubre de 2004. Rol N 3989-2004.

Corte Suprema. 29 de marzo de 2006. Rol No 888-2006.

Corte Suprema. 3 de mayo de 2006. Rol N 1648-2006.

Corte Suprema. 22 de noviembre de 2006. Rol No 5725-2006.

Corte Suprema. 20 de junio de 2007. Rol No 2425-2007.

Cortez Matcovich, G. (2006) El recurso de nulidad: doctrina y jurisprudencia. Santiago: Editorial LexisNexis. pp. 39-40. "Esta concepción restrictiva y formalista del recurso de nulidad obedece a las más variadas justificaciones, debiendo reconocerse la creatividad que en este aspecto exhibe la jurisprudencia nacional, llegándose, en casos extremos, al establecimiento de causales de inadmisión no previstas por el legislador". 
amplio, no sujeto a demasiados rigores formales, que superaba los problemas de la casación, y que cumplía con la garantía constitucional de acceso al recurso que, se agregaba, no suponía necesariamente una revisión de los hechos y, por tanto, no requería que ese recurso tuviera que ser de apelación"12 13 .

De este modo -siguiendo a Riego- ya que nos referimos a "un recurso que comparte elementos con la casación, pero que busca superar algunos de sus problemas, haciéndolo más accesible dado su carácter de único recurso contra la sentencia emanada de un juicio oral"14, en el que, además, los acentos vienen puestos en el recurso como derecho ${ }^{1516}$ y como garantía del justiciable ${ }^{17}$, concluir que la balanza debiera también inclinarse en aras de su efectivo reconocimiento, antes que en relevar su carácter formalista y restrictivo, no debiera representar una dificultad. Mal que mal la opción del legislador fue, justamente, transitar desde un sistema de control vertical hacia uno de corte horizontal, como proyección de un juicio oral entendido como centro neurálgico del sistema en la formación de la convicción, y en el que -en palabras de DAMASKA- "la decisión inicial es posiblemente la final"18.

Lastimosamente, sin embargo, la realidad de los hechos ha terminado por imponer -en materia de recursos- una tesis tan restringida como formalista que, finalmente, no ha hecho sino residenciarse en las antípodas de aquella que fue su idea original.

Ya lo hemos señalado también a propósito del sistema recursivo laboral $^{19}$, que el derecho a recurrir (limitado en cuanto a sus objetivos) que se consagró en el reformado procedimiento penal (hace ya 15 ańos) no puede ser objeto de cortapisas más allá de las impuestas por la ley; podemos criticar su configuración poco adecuada como un mecanismo de cuestionamiento centrado fundamentalmente en aspectos jurídicos, pero no podemos dejar de señalar que como arbitrio procesal existente en nuestra ley y que está a disposición de las partes, no puede ser objeto de restricciones

\footnotetext{
12 Palomo (2010) 495.

13 En el mismo sentido Bofill Genzsch, J. (2005) "Proceso Penal”. Revista de Derecho de la Universidad Adolfo Ibáñez. №2, P. 719; Contez (2006) 37.

14 Riego Ramírez, C. (2007) “El recurso de nulidad en el nuevo sistema procesal penal”. En: Estudios de derecho en homenaje a Raúl Tavolari Oliveros. Romero Seguel, A. (Coordinador). Santiago: Editorial LexisNexis, p.440.

15 Art. 8.2 de la CADH y 14.5 del PIDCP.

16 Sobre el "derecho al recurso y su incardinación normativa en la Constitución como parte del debido proceso o del justo y racional procedimiento", citando abundante doctrina del Río Ferretti, C. (2012) "Estudio sobre el derecho al recurso en el proceso penal". Revista de Estudios Constitucionales. No 1, p. 254.

17 PalOMO (2010) 496.

18 Damaska, Mirjan (1986) Las caras de la justicia y el poder del estado. Análisis comparado del proceso legal. Santiago: Editorial Jurídica de Chile, pp.87-88. Palomo y Valenzuela (2011) 409.
} 
formalistas más profundas que las que vienen desde lo dispuesto por el legislador, las que han hecho evidente la concepción "casacional" que de la naturaleza del recurso tienen varios ministros de Cortes, transformándolo en un recurso doblemente excepcional.

En las líneas que siguen, a partir del análisis que realizaremos sobre un tema actual, como es la toma de muestras biológicas de los adolescentes condenados para su posterior incorporación en el registro de huella genética, y el debate generado en torno a su procedencia, demostraremos que el riguroso criterio de admisibilidad, tan utilizado por la Corte Suprema en la mayor parte de temas, no ha respondido a un criterio de uniformidad temporal, sino que, por el contrario, la mayor o menor flexibilidad en la "puerta de entrada" ha sido, por sobre todo y más allá de formalismos, tributaria del interés específico de la Corte por intervenir en algún tema.

El punto, lejos de inocuo, indebidamente enreda el principio de igualdad que la Corte está llamada a preservar respecto de quien, puesto en idéntica situación y con prescindencia del mayor o menor interés que el asunto suscite, espera de aquella un pronunciamiento similar.

Subsecuentemente, si a la ya cuestionada eficacia del recurso de nulidad -atendido el restringido ámbito competencial con que fue dotado por el CPP al proscribir una revisión integra de lo resuelto- se agregan barreras "de entrada" que comprometen también su admisibilidad, la incorporación ahora del "interés en la materia" en función del cual la Corte actuará con mayor o menor flexibilidad en el testeo de calidad, constituirá un factor de escape, altamente indeterminado y discrecional, que definitivamente arriesgará el "derecho al recurso" como garantía del justiciable, transformándolo finalmente en una mera declaración de voluntad.

\section{2) UNA MIRADA AL ORIGEN DEL ASUNTO}

\section{1.) LA LEY $\mathrm{N}^{\circ} 19.970$}

El 28 de noviembre de 2008 entró en vigencia la Ley $\mathrm{N}^{\circ} 19.970$ que creó el Sistema Nacional de ADN. La publicación de dicho texto, sin embargo, había ocurrido el 6 de octubre de 2004; período de vacancia legal que estuvo supeditado a la publicación en el Diario Oficial del respectivo Reglamento. La finalidad investigativa de la creación de este sistema había sido ya develada por el propio ejecutivo en su Mensaje, al expresar que su propósito era "facilitar el esclarecimiento de los hechos que sean objeto de una investigación criminal, particularmente en lo relativo a la identificación de las personas que fueren responsables del mismo" ${ }^{20}$.

20 Disponible en http://www.leychile.cl/Navegar?idNorma=231105. [fecha de visita 4 de julio de 2015] 
Precisaba dicho texto que el registro estaría referido a "todo tipo de muestras orgánicas que permitan la extracción de dicho antecedente (la huella genética o mapa de $\mathrm{ADN}$ ), las que se encontrarían dispuestas para el uso del Ministerio Público y de los Tribunales de Justicia de nuestro país, para efectos de servir de base al desarrollo de las investigaciones criminales. Así, una muestra de sangre, semen, saliva e incluso de pelo, podrá servir para un mejor y pronto esclarecimiento de un hecho delictivo, ya sea de naturaleza sexual, corporal e incluso patrimonial".

\section{2.) LA ORDEN PARA LA TOMA DE MUESTRAS BIOLÓGiCAS. INICIO DE LA CONTROVERSIA}

A tres años de la vigencia la Ley $\mathrm{N}^{\circ} 20.084$, publicado que fue el Reglamento de la Ley $\mathrm{N}^{\circ} 19.970$ en 2008, los tribunales se dispusieron a dar cumplimento al precepto legal que les obligaba a ejecutar la toma de muestras biológicas a los condenados -sin distinción de edad- por alguno de los delitos seńalados en el catálogo legal ${ }^{21}$, ordenando la práctica del examen que posibilitaba el ingreso de su código genético al Registro Nacional de Condenados (RNC). En este contexto, fue la toma de la respectiva muestra a los adolescentes condenados bajo el amparo de la Ley $\mathrm{N}^{\circ} 20.084^{22}$ aquella que, sin duda, dio pábulo al inicio de una enconada controversia entre los operadores del sistema de enjuiciamiento criminal, encabezados por la Defensoría Penal Pública, la que no tardó en exteriorizar su férrea oposición a la inclusión de los adolescentes al RNC. En términos gruesos se sostenía -ya en el 2008- que la toma de muestras biológicas constituía una verdadera sanción para los adolescentes condenados; la que, amén de no estar incluida expresamente en elenco de sanciones establecidas por la Ley $\mathrm{N}^{\circ} 20.084^{23}$, colisionaba de modo frontal

21 Artículo 17.- Incorporación de huellas genéticas de imputados al Registro de Condenados. Cuando, por sentencia ejecutoriada, se condenare por alguno de los delitos previstos en el inciso siguiente a un imputado cuya huella genética hubiere sido determinada durante el procedimiento criminal, se procederá a incluir la huella genética en el Registro de Condenados, eliminándola del Registro de Imputados.

Si no se hubiere determinado la huella genética del imputado durante el procedimiento criminal, en la sentencia condenatoria el tribunal ordenará que se determine, previa toma de muestras biológicas si fuere necesario, y se incluya en el Registro de Condenados. Lo anterior solo tendrá lugar cuando se condenare al imputado por alguno de los siguientes delitos:

a) los previstos en los artículos 141, 142, $150 \mathrm{~A}, 150 \mathrm{~B}, 296 \mathrm{~N}^{o_{s} .} 1$ y 2, $313 \mathrm{~d}, 315,316,348$, 352, 395, 396, $397 N^{o} 1,401,403$ bis, 433, 436 inciso primero, 440, 474, 475, 476, y 480 del Código Penal;

b) los previstos en los Párrafos $1^{\circ}, 5^{\circ}, 6^{\circ}$ y $7^{\circ}$ del Título VII y $1^{\circ}$ y $2^{\circ}$ del Título VIII del Libro Segundo del Código Penal, y c) elaboración o tráfico ilícitos de estupefacientes o delito terrorista (...).

22 Vigente desde el 7 de diciembre de 2005.

23 Artículo 6 ${ }^{\circ}$.- Sanciones. En sustitución de las penas contempladas en el Código Penal y en las leyes complementarias, a las personas condenadas según esta ley solo se les aplicará la siguiente 
con su espíritu, el que realmente conformaba un subsistema normativo absolutamente diverso de aquel establecido en el Código Penal para los mayores de edad, al punto que -como expresa su art. 2- obligaba a tener en consideración el interés superior del adolescente, expresado en el reconocimiento y respeto de sus derechos "en todas las actuaciones judiciales o administrativas relativas a los procedimientos, sanciones y medidas aplicables a los adolescentes infractores de la ley penal".

Múltiples fueron los mecanismos de impugnación tendientes a revertir la toma de muestras biológicas de los adolescentes condenados, dando con ello lugar a la generación de líneas jurisprudenciales perfectamente reconocibles, tanto desde el punto de vista cronológico como argumentativo.

\section{3.) Primera ETAPA. El RECURSo de Protección}

Las Cortes de Apelaciones de nuestro país, por la vía del recurso de protección y a partir del mismo 2008, sistemáticamente, rechazaron las acciones de este tipo ejercidas en representación de los adolescentes condenados. Sustancialmente, los argumentos estribaban -amén de otros que tendremos ocasión de repasar en el presente trabajo- en considerar que el Servicio Médico Legal (SML), el Servicio Nacional de Menores (SENAME) y Gendarmería de Chile (GENCHI), no actuaban de manera ilegal ni arbitraria al proceder a tomar las muestras biológicas respecto de los adolescentes condenados, pues solo se remitían a dar cumplimiento a un mandato legal que, por lo demás, había sido expresamente ordenado por una resolución judicial. Cabe destacar que, como se aprecia en esta primera etapa, pese a ejercer labores de dirección en las reparticiones administrativas señaladas y desempeñarse como meros ejecutores de las sentencias que ordenaban la toma de muestras biológicas, son las respectivas jefaturas de servicio o direcciones regionales a quienes se reprochaba un obrar al margen del orden jurídico constitucional.

De esta forma, fue el recurso de protección aquel que uniformó la acción principal de las defensas, lo que entendemos respondió a una op-

Escala General de Sanciones Penales para Adolescentes:

a) Internación en régimen cerrado con programa de reinserción social;

b) Internación en régimen semicerrado con programa de reinserción social;

c) Libertad asistida especial;

d) Libertad asistida;

e) Prestación de servicios en beneficio de la comunidad;

f) Reparación del daño causado;

g) Multa, y

b) Amonestación.

Penas accesorias:

a) Prohibición de conducción de vehiculos motorizados, y

b) Comiso de los objetos, documentos e instrumentos de los delitos según lo dispuesto en el Código

Penal, el Código Procesal Penal y las leyes complementarias. 
ción estratégica, desde que -como es sabido- "su utilización no excluye ni impide el uso complementario o posterior de cualquier otra acción que contemple el ordenamiento jurídico" 24 .

Entre otros ${ }^{25}$, el fallo de la Ilma. Corte de Apelaciones de Talca, recaído en los autos Rol Ingreso Corte $\mathrm{N}^{\circ} 1528-2008$, de 20 de enero de 2009, constituyó un buen ejemplo de la línea doctrinal asumida en la materia $^{26}$, la que adscribió a un discurso argumentativo prácticamente calca-

24 Palomo Vélez, D. (2009) "Recurso de protección en Chile: luces, sombras y aspectos que requieren cambios”. En: Nogueira Alcalá, H. (Coord.) La ciencia del derecho procesal constitucional. Estudios en homenaje a Héctor Fix-Zamudio en sus cincuenta años como investigador del Derecho. Santiago: Librotecnia, p. 347.

25 En este sentido: Corte de Apelaciones de Puerto Montt. 2 de enero de 2009. Rol N ${ }^{\circ}$ 289-2008, y 9 de enero de 2008. Rol N² 295-2008; Corte de Apelaciones de Rancagua. 26 de diciembre de 2008. Rol N 1091-2008; Corte de Apelaciones de Valparaíso. 19 de enero de 2009. Rol N 610-2008.

26 "CUARTO.- Que para resolver la cuestión sometida a conocimiento de esta Corte, debe tenerse en cuenta, ante todo, que la ley 19.970, fue publicada el 6 de octubre de 2004, pero -por prevención del artículo 24 - entró a regir al publicarse su Reglamento, lo que acaeció el 25 de noviembre de 2008. Dicha ley crea y regula el Sistema Nacional de Registros de ADN, constituido sobre la base de huellas genéticas; indica que la obtención de la huella genética se realizará por profesionales y técnicos que se desempeñen en el Servicio Médico Legal, o en instituciones públicas $o$ privadas acreditadas para tal efecto; y señala que la administración y custodia estará a cargo del Servicio de Registro Civil e Identificación (1). Agrega que el sistema tendrá el carácter de reservado; no podrá ser fuente de discriminación, estigmatización, vulneración de la dignidad, intimidad, privacidad u honra de persona alguna; (2) que los datos tienen el carácter de sensibles acorde ley 19.628; (3) establece varios registros, entre ellos el de condenados; (4) el que contendrá las huellas genéticas de la personas que hubieren sido condenadas en un proceso criminal por sentencia ejecutoriada; (5) y refiere que la toma de muestras biológicas queda regulada según la ley procesal que sea aplicable; (10) en tanto que la incorporación de huellas genéticas de imputados al registro de condenados debe hacerse según las reglas del artículo 17.

QUINTO: Que la ley antes citada no distingue si se aplica a los adultos y a los adolescentes indagados bajo el imperio de la ley 20.084 - que a su vez entró a regir seis meses después de su publicación, efectuada el 7 de diciembre de 2005- o si se aplica solo a los primeros, en virtud de lo cual resulta evidente que no corresponde restringir el ámbito de su aplicación, debiendo entenderse concebida, por tanto, para registrar los datos respectivos de todos ellos, máxime si la ley penal adolescentes no introdujo cambio alguno sobre el particular.

SEXTO: Que, en tal perspectiva, deben considerarse, también, los principios en los cuales se sustenta la ley 19.970, los objetivos que persigue con la determinación de los diversos Registros, las garantías de reserva que establece y las sanciones que previene para el caso que sus reglas sean infringidas, de todo lo cual es dable concluir que la incorporación de los datos de los adolescentes al Registro de Condena, es legitima pues se enmarca en dicho cuerpo normativo.

SEPTIMO: Que la circunstancia que el Servicio Médico Legal y Gendarmería intervengan para que se tomen muestras biológicas o estén próximos a actuar con tal propósito, respecto de adolescentes condenados por sentencia ejecutoriada, se inserta en el cumplimiento del deber que contiene la ley 19.970, por lo que tal actitud no puede ser estimada ilegal ni arbitraria, en tanto recaiga sobre sujetos pasibles de tal medida acorde con lo preceptuado por el artículo 17 del indicado texto legal.

OCTAVO: Que la concreción de tal medida tampoco puede importar la afectación de las garantías constitucionales consagradas en los $N^{\circ} 2$ y 4 del articulo 19 de la Carta Fundamental, puesto que la incorporación de las huellas genéticas no tiene un fin sancionatorio, cabe por igual para todos los que -en el ámbito de la norma legal mencionada en el razonamiento anterior-están condenados por la comisión de un hecho punible, y debido a que la propia ley establece los 
do y que logró configurar una línea jurisprudencial nítida e identificable que, salvas algunas excepciones que confirmaban su vigencia ${ }^{27}$, clausuró el debate sobre la materia y trajo como consecuencia que la toma de muestras biológicas de adolescentes condenados para su posterior inclusión en el RNC, se ejecutara sin mayores sobresaltos.

\section{4.) HaCia la Corte SuPREMA. Un PRIMER INTENTO}

Plenamente conscientes del adverso panorama, se advierten con mayor claridad ya en el 2009, los primeros intentos tendientes a obtener un pronunciamiento de la Corte Suprema que revirtiera la línea jurisprudencial a estas alturas consolidada de las Cortes de Apelaciones de nuestro país, apelándose - para ante aquella- de los sucesivos rechazos de los recursos de protección. En este derrotero se inscribe, entre otros ${ }^{28}$, el fallo de la Excma. Corte Suprema, dictado en los autos Rol No 371-2009, de 9 de junio de 2009, en el que, sin perjuicio de confirmarse lo resuelto por tribunal a quo al no verificarse conculcación de garantía constitucional alguna de aquellas supuestamente amagadas (19 $\mathrm{N}^{\circ} 2$ y $\mathrm{N}^{\circ} 4 \mathrm{CPR}$ ) y más allá de ahondarse en las razones del rechazo, no se logra unanimidad en la misma atendida la disidencia manifestada por el Ministro, don Haroldo Brito Cruz, cuya injerencia a la postre resultará determinante en la doctrina que asumirá la Corte Suprema en la materia que abordamos ${ }^{29}$.

medios para preservar incólumes los derechos invocados en la especie, conviniendo las sanciones en caso que alguno de ellos fuere quebrantado.

NUEVE: Que, por consiguiente, no existe ningún acto ilegal ni arbitrario, atribuible a los recurridos, susceptible de ser corregido a través de la presente vía, y no aparece ninguna garantía de rango constitucional, de las personas por las cuales se recurre, amenazada en su legitimo ejercicio, menos aún perturbada o privada, por lo que no cabe aceptar la presente acción cautelar (...).

27 Corte de Apelaciones de Santiago. 22 de abril de 2009. Rol N 11479-2008.

28 Corte Suprema. 3 de septiembre de 2009. Rol N 4525-2009.

29 Acordada contra el voto del Ministro seńor Brito, quien fue de parecer de revocar la sentencia apelada y hacer lugar al recurso de protección de estos autos, atendidas las razones que siguen:

PRIMERO. - La Ley No 20.084 Sobre Responsabilidad Penal Adolescente, inequivocamente, estableció un subsistema penal especial en favor de los adolescentes infractores de ley completamente distinto del régimen normativo anterior, el que como unico elemento distintivo del estatuto de los adultos preveía un castigo de prisión disminuido. Lo anterior es consecuencia del artículo 40.1 de la Convención sobre Derechos del Niño que dispone que los niños infractores deberán ser tratados de acuerdo con su particular dignidad, cuidando fortalecer valores y su reintegración a la sociedad. Tales criterios normativos son recogidos en la ley citada y generan un conjunto de derechos que legitiman la reacción penal. Se dispone, entonces, de normas penales especiales que solo son aplicables a los jóvenes porque los medios punitivos y toda la reacción ante el ilícito tienen en cuenta que ha de ejecutarse sin desatender el interés superior del niño, esto es brevemente- sin afectar el desarrollo del menor. Lo anterior es directa consecuencia de haberse aceptado que los destinatarios de unas y otras normas, los adolescentes y los adultos, son distintos.

SEGUNDO.- Consecuentemente, ha de aceptarse que estas últimas reglas conforman el subsistema penal aplicable a los adolescentes, que tienen el carácter de especiales, y que las comunes han de entenderse como de aplicación subsidiaria. 
Como se aprecia, las vías de reclamación -en esta etapa- se agotaban con el recurso de apelación y no era posible avizorar la irrupción del recurso de nulidad como vía idónea para revertir el criterio de las Cortes de Apelaciones del país, aún firme en el rechazo de las acciones de protección impetradas. En efecto, las complejidades para lograr configurar adecuadamente una causal de nulidad y las cortapisas puestas en torno a su admisibilidad, profusamente recordadas por la Corte Suprema, tornaban las perspectivas de cualquier intento en su interposición como un acto más bien testimonial.

\section{5.) Giro ESTRATÉGICO DECISIVO. LA VÍA DEL RECURSO DE NULIDAD (ART. 373 LETRA A) CPP)}

Es con nitidez en el 2012 que, ante los sucesivos fracasos tendientes a evitar la toma de muestras biológicas en adolescentes condenados, la asentada línea jurisprudencial existente a nivel de Corte y, por qué no,

TERCERO.- Asi las cosas, la Ley No 19.970 que previno la creación de un registro con las huellas genéticas de todos los imputados y condenados a los efectos de investigaciones futuras por hechos delictivos, y que es anterior a la $N^{\circ} 20.084$ Sobre Responsabilidad Penal Adolescente -esto es al estatuto penal especial-, no es aplicable a los adolescentes, no obstante que su texto no distingue entre adultos y adolescentes. En efecto, ello es asi porque la ley particular opta por la minima intervención y porque, como se ha dicho, no obstante la sanción que se impone, y también mediante ella, se busca la reinserción social del adolescente. En este contexto normativo, no tiene cabida esta sujeción a la autoridad justificada por la sola circunstancia de la sentencia condenatoria, porque para un adolescente, no obstante los resguardos legales, no es intrascendente su inclusión para toda la vida en un registro de este tipo porque con ello se le mantiene entre infractores. Toda vez que en este subsistema el fin de la pena es la reinserción social del menor, toda acción del Estado que no tienda a este objetivo ciertamente lo contraría.

CUARTO. - En concepto del disidente de todo lo anterior deriva que la decisión de extender a los adolescentes esta obligación importa ilegalidad, puesto que como ha quedado demostrado solo es exigible a los adultos.

Por otra parte también vulnera la garantía del numeral $4^{\circ}$ del artículo 19 de la Constitución Política de la República, porque afecta la vida privada y la honra de los adolescentes requeridos no porque la información pueda ser conocida por terceros, sino porque encontrándose garantizados que los antecedentes y hechos más esenciales de cada persona han de ser solo de su dominio, incorporar un registro características genéticas para que queden a disposición de todo investigador criminal inequivocamente lesiona tal garantía, puesto que no se trata de un caso de excepción fundado en circunstancias particulares que lo justifiquen, cual es la manera que debe observarse cuando se deja de aplicar algún derecho garantizado por la Constitución.

QUINTO.- Demostrada la ilicitud de los llamados a proporcionar la muestra y la vulneración de garantías, el disidente estuvo por hacer lugar al recurso y ordenar abstenerse al señor Director Regional del Instituto Médico Legal de requerir muestras biológicas a los efectos de la Ley $N^{\circ}$ 19.970 a los adolescentes por quienes se recurre.

Finalmente es útil señalar que cuando se interpreta la ley no se la desobedece sino, por el contrario, que se la aplica conforme con lo que se entiende es su genuino alcance que también es derivación del ordenamiento jurídico; y que no es posible ejercer la potestad jurisdiccional sin desarrollar este ejercicio intelectual que siempre es ineludible, porque incluso la convicción de que el sentido de una norma determinad a es claro importa haberse hecho el proceso de interpretación, puesto que tal certeza no puede ser un acto intuitivo (...)". 
las perspectivas de éxito que podían proyectarse a partir de la disidencia planteada en la Corte Suprema por el Ministro Sr. Brito, la Defensoría Penal Pública se decide a abandonar definitivamente el ejercicio de la acción constitucional de protección y sustituirla por el recurso de nulidad, a través de la invocación de la causal contenida en el art. 373 letra a) CPP, cuyo conocimiento corresponde exclusivamente a la Excma. Corte Suprema, incoándose así una suerte de tercera etapa cuyos resultados favorables no tardaron en llegar, consolidándose un trazado argumental que, salvo una muy calificada excepción ${ }^{30}$, perdura hasta nuestros días. En efecto, pese a no verificarse mutación argumentativa relevante alguna, se generó una nueva línea jurisprudencial de nuestro más alto Tribunal ${ }^{31}$ que, nuevamente, clausuró el debate, ahora acogiendo -sin vacilación- cuanto recurso de nulidad fuera promovido por la defensa técnica de los adolescentes condenados, de quienes se pretendía obtener muestras biológicas.

Por lo relevante, insistimos a riesgo de reiteración: exceptuando aquel argumento nuevo que sirvió de puerta de entrada a la causal de nulidad invocada sin excepción por la defensa, los fundamentos de la Corte no sufrieron variación alguna y se circunscribieron, en suma, a solo dos: 1) infracción al debido proceso por no estar precedida la resolución del tribunal de un debate previo entre los intervinientes previa a la dictación de la sentencia que disponía la toma de muestra biológica (argumento nuevo), por una parte; y 2) la imposibilidad de condenar al infractor mediante la imposición de un correctivo ajeno al catálogo de sanciones contenido en la Ley $\mathrm{N}^{\circ} 20.084$, por la otra.

Esta nueva premisa contenida en el art. 373 letra a) CPP, y constituida por la afectación sustancial de derechos o garantías asegurados por la Constitución o por los tratados internacionales ratificados por Chile y vigentes que, potencialmente, importaba la ausencia del debate previo a la sentencia, habilitaba ahora a la Corte Suprema, no ya únicamente a reprochar actos ilegales o arbitrarios cometidos por órganos administrativos ejecutores de la resolución de un tribunal, sino que, antes bien, a declarar la nulidad del juicio oral y de la sentencia dictada por aquel juez que omitió abrir debate entre los intervinientes respecto de la procedencia o no de la toma de muestra biológica del adolescente condenado.

Así, luego de reiterar algunos conceptos del debido proceso y cómo en diversos fallos se ha relevado su trascendencia, la Corte expresa:

\footnotetext{
30 Corresponde a un muy reciente fallo, dictado por la Corte de Apelaciones de Talca con fecha 12 de junio de 2015, en causa Rol N³00-2015, en el que, apartándose de la línea jurisprudencial seguida por la CS, rechaza un recurso de nulidad deducido por la defensa, con base a la causal del art. 373 letra b) CPP, estimando que la sentencia cuestionada no impuso una sanción adicional no prevista por el legislador, por no reunir la naturaleza de aquella.

31 En esta línea se inscriben los siguientes fallos: Corte Suprema. 31 de julio de 2012. Rol $\mathrm{N}^{\circ}$ 4760-12; 7 de noviembre de 2012. Rol No6711-12; y 19 de noviembre de 2012. Rol N ${ }^{\circ}$ 7098-12.
} 
"NOVENO: Que, el persecutor penal, es el exclusivo motor del proceso penal en vigencia, por lo que resulta agraviante para la igualdad de posiciones de las partes que el tribunal concurra a suplir o corregir deficiencias en esa actividad, incorporando a su cometido de órgano jurisdiccional objetivo e imparcial, una actividad ajena al mismo, como la incorporación de oficio de sanciones que ni siquiera han sido pedidas por alguno de los intervinientes ni sometidas a escrutinio para justificar su procedencia, surgiendo una especie de "subsidio procesal" brindado por el juez en beneficio de las posiciones del Ministerio Público o parte que -conforme se comprobó de los audios que fueron escuchados en la audiencia- no efectuó ningún planteamiento al respecto.

DÉCIMO: Que, en este escenario, el adolescente imputado fue puesto en una situación desfavorable o desventajosa, ya que por la irregular actuación del Juez de Garantía se vio privado de la posibilidad de obtener en el ejercicio de sus derechos como interviniente -que debe estar en absoluta igualdad de posiciones respecto de su oponente-, una decisión jurisdiccional favorable, experimentando así, el perjuicio trascendente requerido por la nulidad procesal.

UNDÉCIMO: Que, de esta forma ha quedado en evidencia que el actuar del magistrado referido significó el quebrantamiento de las normas relativas al debido proceso que garantiza la Constitución Política de la República en el artículo $19 \mathrm{~N}^{\circ} 3^{\circ}$, inciso $6^{\circ}$, siendo forzoso concluir que la sentencia recaída en el procedimiento simplificado en análisis es nula”32.

\section{6.) ¿ABANDONO DEL PARADIGMA FORMALISTA O, SIMPLEMENTE, UNA EXCUSA PARA "ENTRAR AL FONDO"?}

Ya hemos constado en otra oportunidad la instalación en nuestras Cortes de "criterios formalistas y restringidos al momento de decidir la admisibilidad del recurso de nulidad, declarándolo expresamente o no, para preservar la "excepcionalidad" que se le reconoce"33. Con razón identifica Nieva, por su parte, una especie de automatismo que rodea la etapa de admisibilidad, la que, según expresa, "va a venir dominada por el sesgo de confianza en el juicio emitido, puesto que la existencia de jurisprudencia, precisamente en el ámbito de un tribunal que cuida especialmente de ella, hace que las líneas jurisprudenciales sean muy difíciles de modificar y, por tanto, cada vez que se inicia una tendencia sobre qué se considera "defecto" en la fase de admisión, sea casi imposible modificar

\footnotetext{
32 Corte Suprema. 31 de julio de 2012. Rol No 4760-12.

33 Palomo y Valenzuela (2011) 408.
} 
la línea jurisprudencial en cuestión"34. En términos ilustrativos cita este autor los dichos de un extinto magistrado del Tribunal Supremo cuyo nombre, lógicamente, omite: "la jurisprudencia es el mantenimiento de los errores propios durante un cierto tiempo" 35 .

Tal como veremos, la Corte Suprema en esta tercera etapa, y en lo que a toma de muestras biológicas de adolescentes condenados se refiere, optó, derechamente, por relajar el excesivo formalismo del que durante años hizo gala para evitar conocer otra clase de materias ajenas a su interés, y que le caracterizó por aplicar un criterio restrictivo a ultranza en el control de admisibilidad. Nuestro más Alto Tribunal, en efecto, por la vía de la inadmisibilidad o de la remisión ${ }^{36}$, se abstuvo de conocer prácticamente la totalidad de recursos de nulidad interpuestos con fundamento en la causal del art. 373 letra a) CPP.

El fundamento sustantivo de esta flexibilización no podemos en este trabajo descubrirlo y su hallazgo exorbita con creces sus fines. El fundamento adjetivo del giro, sin embargo, no nos debe anquilosar al punto de renunciar a inquirir, al menos, acerca de las razones que llevaron a nuestra Corte Suprema a trasponer cortapisas otrora inexpugnables en el control de admisibilidad y que eran objeto casi -parafraseando a Nieva- de un "enjuiciamiento prima facie" 37 . Es evidente que, según señalaremos, puesta la Corte en el trance de optar entre adentrarse al conocimiento amplio de ciertas materias que ha estimado como relevantes o, al menos, de su interés ${ }^{38}$, y el sacrificio de ciertos principios de admisibilidad que pudieran en alguna medida obstaculizarlo, abdicará de estos últimos aún a costa de verdaderas fintas o subterfugios procesales.

Razonablemente, no puede arribarse a una conclusión diversa de la expresada si se tienen en vista los fundamentos que la misma Corte Suprema entrega en los considerandos arriba transcritos.

La Corte reprocha al juez haber asumido una especie de "subsidio procesal" con el Ministerio Público (motor del proceso penal, según sus palabras), al incorporar de oficio en la sentencia sanciones que no fueron solicitadas por él, ni por interviniente alguno, ni someter aquellas a debate previo sobre su procedencia, infringiendo así el principio de igualdad de posiciones.

Nieva Fenoll, J. (2007) Enjuiciamiento prima facie. Barcelona: Editorial Atelier, p. 169.

Nieva (2007) 169.

Art. 383 CPP.

Nieva (2007) 58.

Carece nuestro país de mecanismos de selección discrecional de los recursos en función del especial interés, relevancia o grado de polémica que el asunto genere, tales como el "leave to appeal", en el Reino Unido, o el "Writ o certiorari", en EE.UU. (sobre el particular, véase Nieva Fenoll, J. (2010) El recurso de casación. Santiago: Editorial LegalPublishing, pp. 2023. 


\subsection{1.) Toma de muestras biológicas, ¿̨una sanción?}

Los registros de $\mathrm{ADN}$ son herramientas investigativas creados en función de la persecución penal, cuya reglamentación está confiada a la Ley $\mathrm{N}^{\circ} 19.970$ y el CPP. El art. 27 de la Ley $\mathrm{N}^{\circ} 20.084$, en efecto, señala que la "investigación y juzgamiento de la responsabilidad por infracciones a la ley penal por parte de adolescentes se regirá por las disposiciones contenidas en la presente ley y supletoriamente por las normas del Código Procesal Penal". Fue el CPP, precisamente, el cuerpo normativo que incorporó los artículos 198 inciso $3^{\circ}$ y 199 bis, que expresamente se remiten a la Ley $\mathrm{N}^{\circ} 19.970$, que crea el Sistema Nacional de Registro de ADN, cuyo único propósito fue el de "facilitar el esclarecimiento de los hechos que sean objeto de la investigación criminal, en relación a la identificación de las personas que resultaren responsables de ellos, la que se efectúa mediante el cotejo de las huellas biológicas pesquisadas con aquellas que se encuentren incorporadas en dicho registro; es preciso señalar que ella tiene por objeto contribuir a la investigación criminal y búsqueda de personas perdidas mediante la comparación de sus perfiles genéticos" 39 .

La incorporación de una huella genética al Registro de ADN carece del carácter de sanción o pena principal o accesoria pues, de haberlo sido, la Ley $\mathrm{N}^{\circ} 20.084$-posterior a la Ley $\mathrm{N}^{\circ} 19.970$ - la hubiese contemplado dentro del catálogo de sanciones que describe en su art. 6 , sin que dicha omisión puede ser atribuida a un olvido del legislador juvenil, sino que, por el contrario, a que jamás tuvo ese carácter.

\subsection{2.) La igualdad de posiciones, ¿̨ulnerada?}

No deja de sorprender que la Corte pretenda la participación de los intervinientes (en este caso el Ministerio Público) allí donde las normas de procedimiento ordenan oficiosidad, exacerbando más allá de lo razonable el principio audiatur ex altera parte. Se ha señalado en este sentido que la vigencia del derecho a la igualdad de armas procesales impide -en palabras de Picó I Junoy- "privar de trámites determinados en las normas rituarias de alegación o de contradicción a una de las partes, o crear obstáculos que dificulten gravemente la situación de una parte respecto de la otra" ${ }^{40}$. Como sostienen Maturana y Montero, por la aplicación de este principio "no se pretende la intervención compulsiva de las partes, ni tampoco es necesario que ellas realmente sean oídas, sino que exista la

\footnotetext{
39 Corte Suprema. 8 de junio de 2009. Rol N³71-2009. Considerando Octavo.

40 Picó I Junoy, J. (2012). Las Garantías Constitucionales del Proceso. Barcelona: Bosch Editor, p. 160 .
} 
posibilidad de igual acceso al ejercicio de sus facultades en el proceso. Por eso se seńala que, hoy en día, se cumple con este requisito brindando a la otra parte la ocasión para ser oída" ${ }^{41}$. Así, en consonancia con lo expresado, no deja de ser llamativo que la Corte extrañe y reproche al juez no haber dado lugar al debate, allí donde la ley no lo ha considerado, esto es cuando el contradictorio había ya concluido.

\subsection{3.) Subsidio procesal, ¿por cumplir con la ley?}

En términos sencillos, pero no menos claros, la imparcialidad persigue "salvaguardar la confianza que los Tribunales deben inspirar en una sociedad democrática, por lo que debe garantizarse a las partes que no concurre ninguna duda razonable sobre la existencia de prejuicios o prevenciones en el órgano judicial" 42 . NogueIRA, por su parte, reivindicando el deber de imparcialidad de los magistrados expresa que este implica "ser tercero neutral y desinteresado entre partes, permaneciendo ajeno a los intereses de ellas como al objeto mismo litigioso, examinando y resolviendo el conflicto intersubjetivo solamente sometido al ordenamiento jurídico como criterio de juicio" 43 , bastando esta sola afirmación para despejar cualquier suspicacia de subjetividad que pudiera advertirse en el actuar del juez desde que este no ha hecho sino ceñirse, estrictamente, a cumplir con lo ordenado de modo imperativo por la ley ${ }^{44}$, actuando de forma oportuna (al dictarse la sentencia), rigurosa (al disponer la toma de muestra al condenado con prescindencia de toda distinción que no fuera la comprobación de encuadrarse el delito objeto de condena dentro del catálogo) y oficiosa ( $\sin$ requerimiento de parte).

Siguiendo a Morello en esta oportunidad concordamos en que la "garantía de imparcialidad del juez - pegada al principio de legalidad-, es condición de efectividad de la función decisoria" 45

\subsection{4.) Finalmente, algo sobre la trascendencia}

Mosquera y Maturana, a propósito de la causal de nulidad del art. 373 letra a) CPP, exigen del recurrente en el ejercicio del recurso "esta-

\footnotetext{
41 Maturana Miquel, C. y Montero Lopez, R. (2010). Derecho Procesal Penal. Santiago: AbeledoPerrot. Editorial LegalPublishing. T.II, p. 796.

42 Picó I Junoy (2012) 162.

43 Nogueira Alcalá, H. (2009) "El derecho de acceso a la jurisdicción y al debido proceso en el bloque constitucional de derechos en Chile”. En: Nogueira Alcalá, H. (Coord.) La ciencia del derecho procesal constitucional. Estudios en homenaje a Héctor Fix-Zamudio en sus cincuenta ańos como investigador del derecho. Santiago: Librotecnia, p. 254.

$44 \quad$ Art. 17 Ley $\mathrm{N}^{\circ} 19.970$.

45 Morello, A. (1994) El proceso Justo. Del garantismo formal a la tutela efectiva de los derechos. Buenos Aires: Editorial Abeledo Perrot, p. 418.
} 
blecer el derecho que ha sido desconocido y las razones por las cuales se encuentra este dentro de aquellos que deben ser respetados para encontrarnos frente a un debido proceso, sin perjuicio además de que su infracción debe haber sido sustancial, para los efectos de conducirnos a respetar el principio a que la nulidad sin perjuicio no opera" $46{ }^{47}$. No basta con constatar -tantas veces se ha dicho- la presencia de cualquier omisión, si su ausencia no solo carece de sustancialidad, por una parte, sino que, además, de cualquier influencia en lo dispositivo del fallo, por la otra. Afirma López que "no toda infracción determina automáticamente la nulidad del juicio oral y la sentencia. El carácter sustancial de la infracción supone, en primer lugar, que la infracción sea de tal entidad que comprometa los aspectos esenciales de la garantía, decisión que debe ser adoptada sobre la base del criterio de proporcionalidad. En este punto la idea de infracción sustancial podría ser perfectamente asociada a la teoría del entorno jurídico desarrollada por la jurisprudencia alemana en relación con la prueba ilícita, que exige que la infracción constitucional alegada afecte en forma esencial el ámbito de derechos del recurrente y no sea de una importancia secundaria o no tenga importancia alguna para él”48. La propia Corte Suprema, ha resuelto:

"Que, asimismo, esta Corte ha señalado que el referido arbitrio de impugnación debe entenderse regido por los mismos principios y reglas generales que gobiernan la nulidad procesal; por consiguiente para su procedencia deben concurrir los presupuestos básicos de estas, entre las cuales se encuentra el llamado "principio de trascendencia” que, por lo demás, recoge el artículo 375 del Código Procesal Penal, en virtud del cual se ha sostenido que la trasgresión que funde un recurso de la naturaleza como el de la especie, debe constituir un atentado de tal entidad que importe un perjuicio al litigante afectado, que conduzca a la ineficacia de la garantía, resultando de ello un desconocimiento del núcleo esencial de esta, privándola de eficacia. En otras palabras, se requiere que el vicio sea sustancial, trascendente, de mucha importancia o gravedad, de suerte que el defecto entrabe, limite o elimine el derecho preterido" 49 .

Seguimos a López, finalmente, en cuanto sostiene que "para que la infracción sustancial de derechos o garantías pueda servir, así, de fundamento suficiente a un recurso de nulidad, debe haber "ocasionado a los

\footnotetext{
46 Mosquera Ruiz, M. y Maturana Miquel, C. (2010) Los recursos procesales. Santiago: Editorial Jurídica de Chile. 2a. Ed., p. 336.

47 Proyección de lo señalado es, asimismo, lo dispuesto en el art. 375 CPP. Defectos no esenciales. No causan nulidad los errores de la sentencia recurrida que no influyeren en su parte dispositiva, sin perjuicio de lo cual la Corte podrá corregir los que advirtiere durante el conocimiento del recurso

48 Horvitz y López (2004) 414-415.

49 Corte Suprema. 10 de mayo de 2006. Rol N 897-2006. Considerando Tercero.
} 
intervinientes un perjuicio reparable solo con la declaración de nulidad", que existirá "cuando la inobservancia de las formas procesales atenta contra las posibilidades de actuación de cualquiera de los intervinientes en el procedimiento" conforme lo previsto en el art. 159 CPP"50.

\section{7.) UN LLAMADO A LA FRANQUEZA. ROL DE LAS FORMALIDADES}

Sin muchas vueltas ¿puede razonablemente sostenerse la existencia de una vinculación sustancial entre la ausencia de debate decretado por el juez previo a ordenar en la sentencia la toma de muestras biológicas cuando la misma se encuentra expresamente ordenada por ley ${ }^{51}$, cuando aquel no constituye un requisito especialmente exigido, respecto del cual la ley tampoco contempla una específica sanción? Ciertamente, no, pues resulta evidente que el tribunal al ordenar la extracción al adolescente de muestras biológicas, conforme ordena el art. 17 de Ley $\mathrm{N}^{\circ} 19.970$, no hace sino cumplir un mandato legal cuya exigibilidad solo recae en él, con o sin debate previo, el que carece, por lo demás, de toda eficacia.

Convengamos, entonces, que la Corte Suprema -al menos en lo que a extracción de muestras biológicas de adolescentes condenados se refiere-, conforme la línea jurisprudencial seguida desde el 2012 a la fecha, optó por conocer el fondo del asunto y trasponer así la tan mentada rigurosidad en el examen de admisibilidad que tantas veces enarboló como garantía de la excepcionalidad del recurso de nulidad, sacrificándola en función de su interés en la materia, tomando así distancia de aquel rezo casi sacrosanto que tantas veces tensionó -hasta límites bien peligrososel derecho al recurso entendido como garantía del justiciable, al subyugar su rol al de las formalidades en su interposición.

En este derrotero útil resulta traer a colación parte de la sentencia del Tribunal Constitucional español N ${ }^{\circ} 36 / 1986$, de 12 de marzo del mismo ańo, en la que se manifiesta:

"Los requisitos formales no son valores autónomos que tengan sustantividad propia, sino que solo sirven en la medida en que son instrumentos para conseguir una finalidad legítima. Por ello, los trámites formales no deben ser exigencias cuyo cumplimiento presente siempre el mismo valor obstativo que operaría con independencia, en principio, de cuál sea el grado de inobservancia del requisito, su trascendencia práctica

Horvitz y López (2004) 415.

Art. 17 Ley N ${ }^{\circ}$ 19.970.- "Cuando, por sentencia ejecutoriada, se condenare por alguno de los delitos previstos en el inciso siguiente a un imputado cuya huella genética hubiere sido determinada durante el procedimiento criminal, se procederá a incluir la huella genética en el Registro de Condenados, eliminándola del Registro de Imputados.

Si no se hubiere determinado la huella genética del imputado durante el procedimiento criminal, en la sentencia condenatoria el tribunal ordenará que se determine, previa toma de muestras biológicas si fuere necesario, y se incluya en el Registro de Condenados" 
o las circunstancias concurrentes del caso. Al contrario, han de analizarse teniendo presente la finalidad que pretende logarse con ellos para, de existir defectos, procederse a una justa adecuación de las consecuencias jurídicas con la entidad real del derecho mismo, medida en función de la quiebra de la finalidad última que el requisito formal pretendía servir" 52 .

Concordamos con Fernández al manifestar que no se trata "de eliminar el cumplimiento de condiciones o requisitos, por el solo hecho de tratarse de formalidades, sino que de ser cuidadoso para que esa vía no se transforme en excusa que conduzca a entorpecer o privar de la igual protección en el ejercicio de los derechos" 53 , prevención que, lastimosamente, parece haber olvidado nuestro Máximo Tribunal al restringir, en función de su especial interés, la amplitud que como medio de impugnación tuvo en su génesis la nulidad. Y es que, efectivamente, en un sistema cuyo centro neurálgico está constituido por el juicio oral, en el que el régimen recursivo abandona el carácter vertical, limitándose fuertemente y alzando como único medio de impugnación de la sentencia dictada en un juicio oral el de nulidad ${ }^{54}$, resulta poco sensato exacerbar el rol de las formalidades por sobre el de los derechos (particularmente el del derecho al recurso), considerando que aquél ahora se "reemplaza por la consecución de una intervención de los interesados en la producción misma de la decisión judicial, es decir, de un control que podría denominarse horizontal, que es lo propio del proceso jurisdiccional" 55 .

\section{8.) CONCLUSIONES}

No reprochamos de la Corte esta singular flexibilización del criterio de admisibilidad en la materia que abordamos, por más que controvirtamos el fondo de lo resuelto. Esta relajación en la "puerta de entrada",

52 Citado por Figueruelo Burreiza, Á. (1990) El derecho a la tutela judicial efectiva. Madrid: Editorial Tecnos, p. 90.

53 Fernández Salazar, M. (2007) "Notas sobre el derecho constitucional a defensa jurídica". En: Romero Seguel, A. (Coord.) Estudios de derecho en homenaje a Raúl Tavolari Oliveros. Santiago: Editorial LexisNexis, p. 501.

54 Lo hemos dicho antes, siguiendo a Lorca Navarrete. La opción apareja consecuencias y no es gratuita desde el punto de vista de la perspectiva de los justiciables. Bien lo ha apuntado el citado autor cuando dice que "el carácter ordinario o extraordinario del recurso incide de manera diversa sobre el acceso a la tutela judicial efectiva mediante el recurso". Cuando el sistema recursivo permite que conjuntamente con el recurso ordinario (apelación), se pueda acceder a otra instancia procesal ad quem mediante el recurso extraordinario, la tutela judicial efectiva es más determinante. En cambio, cuando el sistema impone que se pase directamente a la vía extraordinaria, sin existir un acceso previo a la vía ordinaria del recurso, el logro de la tutela judicial efectiva es claramente menos incisiva y penetrante. LorCA Navarrete, A. (2000) Tratado de Derecho procesal civil. parte general: el nuevo proceso civil. Madrid, Editorial Dykinson, p. 1026.

55 Carocca Pérez, A. (2005) Manual El Nuevo Sistema Procesal Penal. Santiago: Editorial LexisNexis, p. 269. 
creemos, incardina perfectamente con la real dimensión que las formalidades han de ostentar en un horizonte que conciba al recurso como derecho del justiciable. Si admitimos que "lo que se pretende es permitir que el recurso efectivamente permita que todo condenado que tenga razones para impugnar el fallo en su contra pueda obtener una oportunidad para hacerlo y no se vea limitado por razones formales" 56 , entonces la Corte ha fallado correctamente, reforzándose este criterio con mayor vigor a partir de lo resuelto por la Corte Interamericana en la Sentencia de 2 de julio de 2004 (caso Herrera Ulloa vs. Costa Rica), al expresar que "el derecho al recurso del art. 8.2 letra h) implica que "La posibilidad de 'recurrir el fallo' debe ser accesible, sin requerir mayores complejidades que tornen ilusorio este derecho" 57 ; más aún cuando hoy se admite que "una revisión integra de la sentencia parece ser el giro o expresión al uso en la jurisprudencia internacional para la interpretación de los arts. 14.5 PIDCP y 8.2 $\mathrm{CADH}$, y que apunta indubitadamente a la naturaleza (amplitud) del examen para entender satisfecho el derecho al recurso en esta específica faceta" 58 , dado que el excesivo formalismo atenta contra la única y limitada posibilidad de revisión y cuestionamiento de la sentencia ${ }^{59}$.

56 Riego (2007) 443.

57 Citada por Del Río (2012) 257. En efecto, la Corte definió los alcances del recurso apropiado para garantizar el derecho a recurrir consagrado en la $\mathrm{CADH}$. Entre ellos, consignó que el tribunal que revise la sentencia debía tener competencia para conocer con amplitud todos los planteamientos del recurrente y que el medio de impugnación en cuestión debe ser un "recurso ordinario eficaz" que garantice "un examen integral de la decisión recurrida", que vaya más allá de las cuestiones de derecho y que se dirija a una fiscalización exhaustiva y no limitada de "todas las cuestiones debatidas y analizadas en el tribunal inferior".

58 Del Río (2012) 268-269. En el mismo sentido Palomo Vélez, D. y Alarcón Corsi, H. (2011) "Fundamentación de la sentencia y contradicción, como materialización del derecho al recurso en materia procesal penal”. Revista Ius et Praxis. No 1, p.313.

59 Lorca ha recordado que este criterio de la CIDH, lejos de aparecer como una posición aislada y ocasional, ha seguido nutriendo las sentencias que emanan de dicho tribunal internacional. Más aún, la cuestión ha tomado nuevamente ribetes de notoriedad "a raíz del fallo en el caso "Norín Catrimán y otros versus Chile", de 29 de mayo de 2014, en el que nuevamente se plantean cuestiones que son relevantes en lo que hemos venido sosteniendo". "En efecto, si bien la decisión de la CIDH da cuenta que no se logró probar que en virtud de la causal del artículo 374 letra e) del Código Procesal Penal no sea posible revisar cuestiones relativas a la base fáctica del fallo por medio del examen del juicio probatorio del mismo, a renglón seguido plantea que " $[\mathrm{N}]$ o obstante, esta Corte insiste en que la interpretación que los tribunales internos realicen de la referida causal debe asegurar que se garanticen el contenido y criterios desarrollados por este Tribunal respecto del derecho a recurrir el fallo (supra párr. 270). El Tribunal reitera que las causales de procedencia del recurso asegurado por el artículo 8.2.h) de la Convención deben posibilitar que se impugnen cuestiones con incidencia en el aspecto fáctico del fallo condenatorio ya que el recurso debe permitir un control amplio de los aspectos impugnados, lo que requiere que se pueda analizar cuestiones fácticas, probatorias y jurídicas en las que está fundada la sentencia condenatoria”. LoRCA, N. (2015) "El recurso de nulidad laboral y su falta de correspondencia con la garantía del derecho al recurso". En: Palomo Vélez, D. (Coord.) Proceso y Justicia laboral: Lecturas a contracorriente. Santiago: Ediciones Jurídicas de Santiago, p. 313. 
Lo que censuramos de la Corte es la utilización más o menos laxa y ante todo discrecional, de la válvula de la accesibilidad en función del interés inconfesable y específico que aquella mantenga sobre alguna materia, pues ahí sí, verdaderamente, el arbitrio termina por comprometer el principio de la igualdad, que es justamente aquel que la Corte está llamada a preservar, y que en cuentas simples importa -siguiendo a CAROcCa"dar soluciones equivalentes para casos similares"60.

En este sentido, nuestra Corte Suprema en un primer momento echa mano a criterios no contemplados en la ley para limitar el acceso a un recurso ya de por sí limitado en su configuración, para luego mediante otro criterio, tampoco contemplado por la ley, y de suyo discrecional (interés de la Sala de conocer de una determinada materia), abrir la llave de acceso al recurso. De esta forma nuestro máximo Tribunal se comporta como una Corte con amplísimo campo discrecional, que parece más bien ajustarse a las concepciones reconocidas en otros sistemas como el Writ Certiorari estadounidense y el Leave to Appeal Británico. Ambos sistemas se basan en un enfoque diverso que se entrega al recurso y a la función del máximo tribunal en estas legislaciones, en las que se otorga un amplísimo campo de acción discrecional al tribunal para conocer o no de los recursos que les son presentados, dejando ser un derecho del recurrente solicitar la revisión de una sentencia, sino que deriva de la discrecionalidad judicial.

Con agudeza señala TARuffo: "Uno puede escribir o hablar como quiera, todos los estilos pueden ser intercambiables. Yo diría, exagerando un poco, que la única cosa que el juez no puede hacer es decir, yo decidí así, porque así a mí me gustó, porque entonces aquí ya no es una cuestión de estilo" 61.

60 Carocca, A.; Duce, M.; Riego, C.; Baytelman, A.; Vargas, J. (2000) Nuevo proceso penal. Santiago: Editorial LexisNexis, p. 324.

61 Taruffo, M. (2003) "Consideraciones sobre prueba y verdad". En: La prueba en el nuevo proceso penal Oral. Coloma Correa, R. (Editor). Santiago: Editorial LexisNexis, p. 146. 